\title{
Tendência empreendedora do gerente: uma análise de sua relevância para o sucesso de projetos inovadores
}

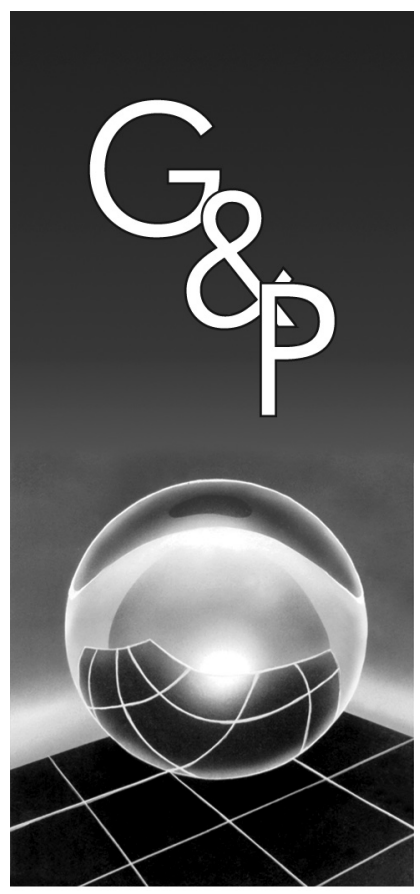

\author{
Rosária de Fátima Segger Macri Russo \\ Roberto Sbragia
}

\begin{abstract}
Resumo
O gerente de projeto, no seu papel de liderança, é um elemento-chave, tanto para o sucesso dos empreendimentos que coordena, quanto para a implementação das estratégias das organizações. Adicionalmente, pode se tornar importante para o futuro da organização, ao usar sua capacidade empreendedora para vislumbrar novas necessidades e oportunidades. No entanto, o gerente de projetos tem responsabilidades operacionais, de planejamento, monitoramento, contabilização e controle do projeto, que muitas vezes contrastam com as características de um empreendedor. Ante essas visões contraditórias sobre o gerente de projetos torna-se relevante avaliar se as características de um empreendedor quando incorporadas no perfil de um gerente se refletem em projetos mais bem sucedidos do ponto de vista empresarial. Para esta avaliação, foi feita uma pesquisa de campo com 164 gerentes de projetos, em sua maioria homens, com estudos de pós-graduação e bastante experientes. A análise não-paramétrica indicou uma tendência de se ter projetos mais bem sucedidos quanto maior for a tendência empreendedora do gerente de projetos. Houve um destaque para a tendência criativa, para a qual se pôde observar um impacto positivo sobre inúmeros critérios de sucesso.
\end{abstract}

Palavras-chave: Gerente de projetos. Empreendedorismo corporativo. Sucesso de projetos. Tendência empreendedora.

\section{Introdução}

Desde o século passado, a humanidade experimenta um ritmo cada vez mais intenso de mudanças, transformações, evolução de conceitos e uso de novas tecnologias. Pode-se comprovar isso pela rapidez com que algumas tecnologias conseguiram ser utilizadas por 50 milhões de pessoas: 74 anos para o telefone, 38 anos para o rádio, 16 para o computador pessoal, 13 para a televisão, 5 para o celular e 4 para a Internet (SIQUEIRA, 2006). Observe-se que, além da rapidez, também há que se considerar sua pronta inserção no ambiente organizacional. A Internet, por exemplo, por si só foi responsável por mudanças significativas no modus operandi das organizações e dos negócios, nos últimos dez anos. Por intermédio da Internet, os negócios passaram a ser feitos entre pessoas e empresas das mais diversas localidades e nacionalidades, barateando o custo de transação. Nesta perspectiva, o mundo dos negócios igualmente demanda evoluções cada vez mais rápidas, exigindo ações empreendedoras imediatas e inovadoras.

Um dos melhores métodos para que a inovação aconteça dentro das organizações é encorajar as pessoas a buscarem a inovação, i.e., a serem empreendedoras dentro da estrutura organizacional na qual trabalham, permitindo que tenham liberdade e recursos para perseguir as suas visões e com isso criar novos empreendimentos (PINCHOT III, 1989). Muitos autores denominam essa pessoa de empreendedor corporativo (CAIRD, 1991; LUCHSINGER; BAGBY, 1987; LUMPKIN; DESS, 1996), outros de intraempreendedor (PINCHOT III, 1989; HASHIMOTO, 2006). Neste sentido, o empreendedorismo pode ser caracterizado como um processo de criação de algo diferente, com valor, pela dedicação e esforço de alguém que assume os riscos financeiros, psicológicos e sociais e que busca as recompensas resultantes na forma de satisfação pessoal e monetária (HISRICH; PETERS, 1986).

Para Andreassi (2005), deve-se fazer uma distinção entre empreendedorismo corporativo e intraempreendedorismo. O conceito de empreendedorismo corporativo se refere ao processo de um indivíduo ou um grupo de indivíduos de criarem uma nova empresa, dentro de uma organização já existente. O conceito de intraempreendedorismo, por sua vez, se refere a um indivíduo, 
independentemente do nível hierárquico, que possui senso de oportunidade e sensibilidade para os desafios e problemas enfrentados pela empresa na qual trabalha, além da obstinação em resolver esses problemas, se caracterizando assim como um empreendedor.

Para Luchsinger e Bagby (1987), tanto o empreendedor, que cria a sua própria empresa, quanto o empreendedor corporativo dependem fortemente de inovação, mas usam modelos diferentes. Enquanto o primeiro gera seus próprios padrões e tem um risco financeiro maior, o segundo se sujeita ao modelo existente na organização da qual faz parte, com restrições de estrutura e procedimentos, tornando sua tarefa mais difícil, principalmente na busca de patrocinadores para suas idéias. Em contraposição, seu risco financeiro tende a ser menor.

Entretanto, a partir de certo ponto da evolução de uma organização, não basta ter a figura do "empreendedor fundador" como o responsável pelas inovações, uma vez que se torna inevitável que os funcionários e parceiros que atuam cotidianamente em sua estrutura também contribuam efetivamente nesta busca (BIRLEY; MUZYKA, 2001). Reforçando esse ponto, Schumpeter (1949), já no fim da década de quarenta, chamava a atenção para o fato de que a função empreendedora não poderia ser incorporada por uma única pessoa, pois ela deveria ser exercida cooperativamente. Uma idéia simples poderia evoluir a partir da contribuição de outros pontos de vista, como é o caso de pessoas de departamentos diferentes, gerando assim um novo produto, um novo serviço ou mesmo um novo negócio que seja realmente efetivo no mercado.

Nessa linha de raciocínio, uma figura que atualmente desponta no ambiente organizacional é o gerente de projetos. Esse indivíduo pode ser considerado como um elemento-chave para a implementação das estratégias empresariais atuais, principalmente por que ela se dá por meio de projetos inovadores. Pode também se tornar importante para o futuro da organização, ao usar sua capacidade empreendedora para vislumbrar novas necessidades e oportunidades, dada a sua maior proximidade com o ambiente externo, como clientes, fornecedores, parceiros, concorrentes e outros. Adicionalmente, é uma figura relevante por suas responsabilidades operacionais, de planejamento, monitoramento e controle, a fim de assegurar que os objetivos do projeto sejam atendidos. Todavia, para esse último papel, suas características de empreendedor talvez não sejam tão necessárias.

Assim, considerando a importância do empreendedorismo e do gerente de projetos para a adaptabilidade da organização às necessidades de inovações advindas tanto do mercado externo (demand pull) como de seu ambiente interno (technology push), torna-se relevante avaliar se as características de um empreendedor corporativo agregam valor ao gerente de projetos, na medida em que se reflitam em projetos mais bem sucedidos sob diferentes aspectos, incluindo o estratégico. Este é o objetivo deste estudo, que parte da premissa de que o grau de empreendedorismo do gerente é apenas um dos fatores contribuintes para o sucesso dos projetos.

A seguir, apresenta-se uma revisão teórica dos conceitos-chave envolvidos neste estudo, particularmente relacionados ao empreendedorismo, ao desempenho de projetos e à figura de seu gerente. Depois, a metodologia do estudo é apresentada, sendo seguida da análise e interpretação dos dados. Finalmente, apresentam-se as conclusões e as recomendações derivadas do estudo.

\section{Base conceitual}

\subsection{Empreendedorismo e tendência empreededora}

O empreendedorismo é um tema recente. Assim, identificar as características psicológicas de um empreendedor é uma tarefa complexa, que tem sido objeto de vários estudos. Caird (1991) apresenta um teste que separa estas características em cinco dimensões, identificando em seu estudo que os empreendedores de maior sucesso tinham altos scores, em cada uma delas:

a) necessidade de realização: que representa o empreendedor que possui algumas qualidades como: visão futura, auto-suficiência, postura mais otimista do que pessimista, orientação para as tarefas e para os resultados, incansabilidade e energia, confiança em si mesmo, persistência e determinação, além de dedicação para concluir uma tarefa;

b) necessidade de autonomia/independência: representando as qualidades de realização por intermédio de atividades pouco convencionais, preferência por trabalhar sozinho, necessidade de priorizar os seus objetivos pessoais e expressar o que pensa, preferência por tomar decisões ao invés de receber ordens, não se rende à pressão do grupo de trabalho;

c) tendência criativa: que condensa as qualidades de imaginação e inovação, tendência de sonhar acordado, versatilidade e curiosidade, geração de muitas idéias, intuição, gosto por novos desafios, novidade e mudança;

d) propensão a riscos: refletida por qualidades como atuação mesmo com informações incompletas, julgamento quando dados incompletos são suficientes, valorização com precisão de suas próprias capacidades, ambição em um nível adequado, avaliação de custos e benefícios correta, fixação de objetivos desafiadores, mas que podem ser realizados; e

e) impulso e determinação: que representa a tendência do empreendedor possuir as qualidades de: aproveitamento de oportunidades, não aceitação de predestinação, atuação no sentido de controlar 
seu próprio destino, autoconfiança, equilíbrio entre resultado e esforço e considerável determinação.

Complementarmente, as dimensões identificadas por Lumpkin e Dess (1996) estão de certa maneira alinhadas às dimensões supracitadas, mas sob uma visão organizacional. Estes autores também confirmam a problemática da caracterização do empreendedor quando afirmam que as dimensões podem variar de um contexto para outro. De modo análogo, Hashimoto (2006) observa que não se deve esperar que uma mesma pessoa tenha todas as características positivas de um empreendedor corporativo. As dimensões identificadas por Lumpkin e Dess (1996) são:

a) autonomia: que é definida por uma ação independente de um indivíduo ou equipe para gerar uma idéia ou uma visão e realizá-la;

b) inovação: na medida da propensão da organização para inovar; num sentido schumpeteriano de "destruição criativa", i.e., a tendência de se envolver e apoiar novas idéias, experimentos, novidades, por intermédio de um processo criativo que pode gerar novos produtos, serviços e processos;

c) propensão ao risco: podendo-se dizer que ela, numa organização, seria relacionada a incorrer em altas dívidas ou comprometer grande número de recursos para aproveitar uma oportunidade do mercado com a pretensão de obter um maior retorno. Jones e Butler (1992) afirmam que é importante distinguir entre risco e incerteza, já que o lucro do empreendedor está na presença da incerteza. É possível calcular a probabilidade de que um resultado esperado não aconteça e, assim, como para outros fatores, pode-se especificar um preço para incorrer nesse risco. Todavia o empreendedor atua na incerteza e na oportunidade cuja probabilidade não pode ser calculada facilmente, devido ao seu ineditismo;

d) pró-atividade: é a iniciativa pela antecipação e perseguição de oportunidades, assim como a atuação em mercados emergentes; e e) competitividade agressiva: é definida como a propensão de desafiar direta e intensivamente seus competidores para alcançar uma posição de destaque ou, pelo menos, melhorar seu posicionamento no mercado.

Por outro lado, as organizações possuem estratégias estabelecidas para direcionar as ações que visem alavancar e perpetuar o negócio, com resultados satisfatórios não só para os acionistas (shareholders), mas também para todos que participam, ativamente, na efetivação destes resultados (stakeholders). Estas estratégias, em sua maioria, são realizadas por meio de projetos, que se caracterizam por ser um esforço temporário para se gerar um produto, serviço ou resultado exclusivo.

\subsection{Projetos e sucesso}

Por suas características intrínsecas, temporalidade, novidade e unicidade, um projeto já contém certo nível de inovação em seu gerenciamento, além do nível de inovação exigido pela tecnologia a ser empregada em seu produto final. Estas inovações trazem maiores dificuldades na execução, nem sempre resultando em projetos bem sucedidos.

Em uma retrospectiva sobre o entendimento do significado do sucesso do projeto, Jugdev e Müller (2005, p. 23), conforme Figura 1, mostram a evolução deste conceito dentro do ciclo de vida de um produto, seja ele um sistema de computador, um novo remédio ou um foguete da NASA (National Aeronautics and Space Administration). Esta evolução afetou a maneira dos projetos serem gerenciados, já que os objetivos a serem alcançados e as expectativas decorrentes de sua realização também se modificacaram ao longo do tempo.

Kerzner (2003) cita que na década de 1960, vista como o primeiro período conforme Figura 1, o sucesso era medido apenas do ponto de vista técnico, i.e., o projeto era um sucesso se seu produto fosse adequado, segundo normas internas da organização executora. As métricas simples como custo, tempo e especificações eram as mais

Ciclo de vida do produto

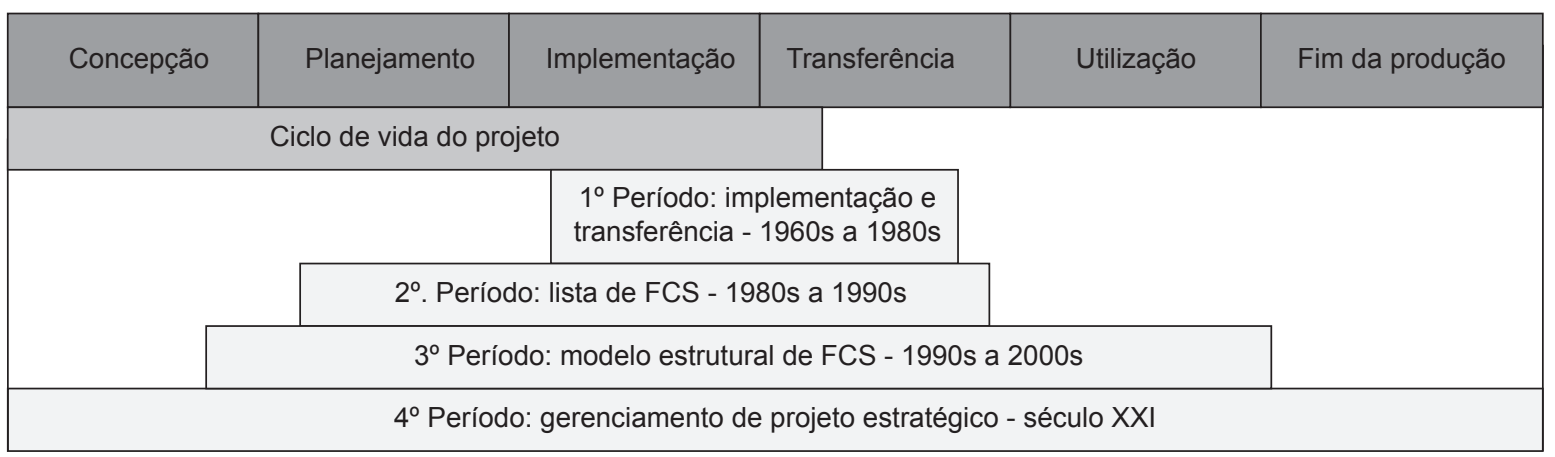

Figura 1. Evolução da mensuração do sucesso em projetos ao longo do tempo. Fonte: Adaptado de Jugdev e Muller, 2005. 
usadas, pois eram simples e atendiam aos critérios da organização-mãe.

Durante os anos 80 e 90, correspondente ao segundo período, o cliente começou ser visto como um fator crítico para o sucesso do projeto, mas a mensuração ainda era única, durante o ciclo de vida do projeto (JUGDEV; MÜLLER, 2005). Começaram a surgir inúmeras publicações com exemplos de projetos bem sucedidos e com lições que deveriam ser apreendidas. As organizações, então, passaram a acreditar que, se utilizassem os mesmos processos, também teriam igualmente sucesso em seus projetos. Embora algumas tenham conseguido seu intento dessa forma, essa metodologia não garantia o sucesso, dado que não se identificava o contex to no qual os processos eram criados. Várias listas, então, com fatores críticos de sucesso (FCS) foram criadas, como a descrita por Cleland (1999): falta de entendimento da complexidade do projeto; problema de comunicação interna; falha na integração de elementos-chave; controle inadequado; falta de controle nas mudanças dos requerimentos do projeto; estratégia de execução ineficiente; demasiada dependência de software; expectativas diferentes entre o contratante e o contratado; negociações sem o espírito de "ganha-ganha"; educação e treinamentos falhos; falta de comprometimento da liderança e do patrocinador.

No início do terceiro período (1990-2000), visualizam-se os FCS dentro de determinados modelos, de maneira a avaliar inúmeros critérios, englobando não somente os fatores internos ao projeto, mas também os externos. Acompanhando essa evolução, o significado de sucesso em projetos também se tornou um pouco mais abrangente, conforme três modelos descritos a seguir. Assim, citando o primeiro deles, Pinto e Slevin (1988), a partir da premissa que o sucesso é subjetivo e depende do ponto de vista da pessoa que o está avaliando, representam o sucesso em três círculos concêntricos: i) validade técnica do projeto, que procura avaliar até que ponto o resultado do projeto funciona como estava previsto para funcionar, sendo este considerado o critério básico; ii) validade organizacional, que procura avaliar até que ponto os resultados obtidos foram ao encontro das necessidades do cliente; e iii) efetividade organizacional, que procura avaliar até que ponto os resultados, após a conclusão do projeto, foram usados pelo cliente e, conseqüentemente, contribuíram para melhorar seu desempenho e/ou de sua organização. Sucesso, segundo os autores, significa obter altos scores nas três dimensões.

Em outro estudo, Sbragia et al. (1986) identificaram três possíveis dimensões para avaliação do sucesso dos projetos, ligadas ao horizonte de tempo: i) critérios imediatos, avaliados pelo padrão técnico, custo, prazo e satisfação do cliente; ii) critérios intermediários, avaliados pela imagem institucional, pelo crescimento da equipe, relações comerciais estabelecidas e capacitação técnica da organização; e iii) critérios finais, avaliados pela contribuição para a sobrevivência, crescimento, desenvolvimento institucional a curto, médio e longo prazo.

Finalmente, Shenhar et al. (1997) desenvolveram um estudo baseado em um modelo multidimensional, reconhecendo que pessoas diferentes têm percepções diferentes de sucesso, ao mesmo tempo em que reafirmam que esta percepção varia no tempo. Assim, tais autores propõem uma avaliação em quatro dimensões:

a) eficiência do projeto: analisa se o projeto terminou dentro do prazo e do orçamento, sendo que algumas instituições podem acrescentar alguns indicadores próprios de seu segmento de mercado, como quantidade de alterações no produto antes de ser disponibilizado para venda;

b) impacto no cliente: refere-se ao atendimento dos requerimentos e necessidades reais do cliente e/ou usuário final, mas também relativa à satisfação do cliente com o produto e a quanto está propenso a comprar uma extensão do projeto;

c) impacto direto no negócio: avalia o impacto que o projeto terá na organização, como, i.e., na sua participação dos lucros, ou quantos negócios alavancará, ou ainda se aumentará a participação da empresa no mercado, contanto que os impactos sejam de curto prazo; e

d) preparação para o futuro: avalia quanto o projeto ajudou na construção da infra-estrutura da organização para o futuro, possibilitando a geração de um novo mercado, uma nova linha de produtos ou uma nova tecnologia.

$\mathrm{O}$ quarto período (século XXI) na evolução da mensuração do sucesso de projetos engloba os estudos que indicam a necessidade não apenas de se completar o projeto com sucesso, mas também de se escolher o melhor projeto no contexto da estratégia da organização. Para selecionar da melhor forma possível os projetos, um tema que surge é sua categorização e priorização dentro de um portfolio que, além de atender à estratégia, também maximize o retorno dos investimentos (CRAWFORD et al., 2006). Complementarmente, essa abordagem ajudou as organizações a desenvolverem e designarem competências apropriadas e específicas para empreender um projeto de maneira bem sucedida. Neste período, o gerenciamento de portfolio e de programas tornaram-se temas preponderantes para um completo entendimento do sucesso dos projetos, sobretudo no seu papel de executores da estratégia das organizações (MORRIS; JAMIESON, 2004).

\subsection{Gerente de projetos}

Apesar da responsabilidade pelo desempenho e realização do projeto ser da equipe, a responsabilidade 
primária é do gerente de projetos, devendo conhecer e esclarecer as expectativas e os objetivos do projeto a todos os envolvidos. Além do mais, deve assegurar o atendimento desses objetivos, utilizando o gerenciamento básico nas áreas de escopo, tempo, custo, comunicações, recursos humanos, contratos, materiais e risco (DINSMORE, 1993, p. 40).

Para desempenhar esse papel com sucesso, o gerente de projetos deve possuir algumas características. O Quadro 1 apresenta as mais citadas, como resultado de uma ampla revisão bibliográfica. A dimensão mais realçada é a "competência técnica e administrativa", que inclui as práticas de gerenciamento de projetos, denotando um cunho bastante tático da atuação do gerente de projetos. Em termos de características, verifica-se que a "liderança" foi a mais citada pelos autores, com nove menções, seguida de "comunicação", "gerenciamento de conflito" e "negociação", com seis, cinco e quatro menções, respectivamente. Em relação ao empreendedorismo corporativo, só se verifica a preocupação em Kerzner (2001), quando explicitamente menciona o "empreendedorismo", e em Cohen e Graham (2002) e Dinsmore (1992), quando citam as características de "tratamento do projeto como negócio" e "visão externa à organização".

Um ponto que suscita divergência entre o papel do empreendedor corporativo e o do gerente de projetos é que se espera deste último "ousadia em termos de encontrar a melhor solução para os problemas do empreendimento" (RABECHINI JR, 2005). Contudo, espera-se também que o gerente faça apenas o trabalho que tenha sido definido como escopo do projeto (PMI, 2004). Seguindo essa lógica, parece não haver expectativa, portanto, de que o gerente de projetos busque novas oportunidades, mas sim que planeje de uma forma precisa o que foi definido inicialmente, e que realize o planejado da melhor maneira possível.

De fato, Kerzner (2003) argumenta que em muitas empresas o gerente de projetos só é designado após a fase de planejamento e, algumas vezes, desconhece como o projeto se enquadra nas metas e estratégias globais da organização. $\mathrm{O}$ autor comenta adicionalmente que, no futuro, esta situação se alterará, pois o gerente de projetos terá autoridade para agir como um catalisador de mudanças, já que desempenhará cada vez mais um papel central quanto ao cumprimento das metas financeiras da organização.

\section{Metodologia}

A fim de viabilizar o propósito central deste trabalho, i.e., investigar a relação existente entre os projetos gerenciados por pessoas com características empreendedoras e seu sucesso, fez-se uso de uma pesquisa de natureza descritiva e quantitativa, por meio de um levantamento de campo (survey) transversal (SELLTIZ et al., 1987).

Por aproximação, a população consistiu de gerentes de projetos presentes no cadastro do PMI (Project Mananagement Institute), capítulo São Paulo, sendo que a amostra foi, portanto, não-probabilística e acidental, pois resultou das respostas fornecidas pelos gerentes de projetos que se dispuseram a responder ao questionário. O questionário ficou disponível na Internet, pelo período de 15/10/2006 a 30/11/2006, tendo sido respondido por 313 gerentes de projetos. Apenas 164 instrumentos, porém, foram considerados válidos e utilizados.

Duas limitações decorrem destes procedimentos. A primeira diz respeito ao grau de inferência dos resultados. Evidentemente, a forma como a amostra foi construída e a falta de controle sobre os não-respondentes impossibilita a generalização dos resultados obtidos. A segunda diz respeito aos respondentes. Idealmente, pessoas diferentes deveriam ter sido utilizadas para avaliar as diferentes variáveis do estudo, i.e., empreendedorismo e sucesso dos projetos. Certamente o cliente seria o indicado para esta última. Contudo, todas as pesquisas apresentam restrições de tempo, custo e acessibilidade. Assim, embora, de um lado, reconheça-se que a adição de outros respondentes mais adequados poderia ter modificado os resultados do estudo, de outro, o uso de pessoas próximas ao fenômeno pesquisado, como é o caso do gerente de projetos, também é um procedimento aceitável e amplamente utilizado na área das ciências sociais (SELLTIZ et al., 1987), desde que seus resultados sejam vistos, exclusivamente, do ponto de vista de tais informantes, como é o caso deste estudo.

As organizações executoras do projeto foram, em sua maioria, entidades empresariais privadas (92\%), de capital nacional $(62 \%)$, de grande porte $(70 \%)$, que operavam na área de serviços $(76 \%)$. Os questionários foram respondidos por gerentes de projetos, os quais eram, em sua maioria, pessoas do sexo masculino (78\%), com formação acadêmica e, no mínimo, com estudos de pós-graduação (72\%) e com mais de 32 anos de idade (68\%), portanto com um considerável conhecimento profissional, dado que mais de $54 \%$ possuem mais de 15 anos de experiência.

Para definição das características do empreendedor corporativo, no instrumento de pesquisa foram empregadas as cinco dimensões definidas por Caird (1991) como as características psicológicas mais significativas associadas à pessoa empreendedora, entre as demais citadas na literatura. Para avaliar essas dimensões foi, operacionalmente, utilizado o teste de Tendência Empreendedora Geral (TEG), desenvolvido na Unidade de Formação Empresarial e Industrial da Durham University Business School (atual detentora dos direitos autorais), que contém uma metodologia própria de análise de tendência empre- 
Quadro 1. Características mais citadas do gerente de projetos segundo a literatura.

\begin{tabular}{|c|c|c|c|}
\hline Dimensão & Característica & $\begin{array}{l}\text { Qtde de } \\
\text { citações }\end{array}$ & Autores que citaram a característica \\
\hline \multirow{4}{*}{$\begin{array}{l}\text { Competência técnica } \\
\text { e administrativa }\end{array}$} & Competência administrativa & 3 & Dinsmore, 1992; Kerzner, 2001; Meredith e Mantel Jr., 2003 \\
\hline & Competência técnica & 5 & $\begin{array}{l}\text { Archibald, 2003; Dinsmore, 1992; Kerzner, 2001; Meredith e } \\
\text { Mantel Jr., 2003; Rabechini Jr, } 2005\end{array}$ \\
\hline & Conhecimento de tecnologia & 3 & $\begin{array}{l}\text { Archibald, 2003; Crawford e Cabanis-Brewin, 2006; Dinsmore, } \\
1992\end{array}$ \\
\hline & Conhecimento de projeto & 3 & $\begin{array}{l}\text { Archibald, 2003; Crawford e Cabanis-Brewin, 2006; Dinsmore, } \\
1992\end{array}$ \\
\hline Comunicação & Comunicação & 6 & $\begin{array}{l}\text { Archibald, 2003; Crawford e Cabanis-Brewin, 2006; Dinsmore, } \\
\text { 1992; Heldman, 2003; Rabechini Jr, 2005; Verma, } 1996\end{array}$ \\
\hline \multirow[t]{3}{*}{$\begin{array}{l}\text { Consciência } \\
\text { organizacional }\end{array}$} & $\begin{array}{l}\text { Comprometimento } \\
\text { organizacional }\end{array}$ & 2 & Dinsmore, 1992; PMI, 2002 \\
\hline & Consciência organizacional & 2 & Dinsmore, 1992; PMI, 2002 \\
\hline & Sensibilidade política & 2 & Meredith e Mantel Jr., 2003; Verma, 1996 \\
\hline $\begin{array}{l}\text { Gerenciamento do } \\
\text { estresse }\end{array}$ & Gerenciamento do estresse & 2 & Meredith e Mantel Jr., 2003; Verma, 1996 \\
\hline \multirow[t]{2}{*}{ Liderança } & Impacto e Influência & 3 & Heldman, 2003; PMI, 2002; Verma, 1996 \\
\hline & Liderança & 9 & $\begin{array}{l}\text { Archibald, 2003; Crawford e Cabanis-Brewin, 2006; Dinsmore, } \\
\text { 1992; Heldman, 2003; Kerzner, 2001; Meredith e Mantel Jr., } \\
\text { 2003; PMI, 2002; Rabechini Jr, 2005; Verma, } 1996\end{array}$ \\
\hline $\begin{array}{l}\text { Mensuração de } \\
\text { risco }\end{array}$ & Mensuração de risco & 2 & Cohen e Graham, 2002; Dinsmore, 1992 \\
\hline \multirow[t]{2}{*}{ Negociação } & Gerenciamento de conflito & 5 & $\begin{array}{l}\text { Dinsmore, 1992; Kerzner, 2001; Meredith e Mantel Jr., 2003; } \\
\text { Rabechini Jr, 2005; Verma, } 1996\end{array}$ \\
\hline & Negociação & 4 & $\begin{array}{l}\text { Crawford e Cabanis-Brewin, 2006; Heldman, 2003; Rabechini } \\
\text { Jr., 2005; Verma, } 1996\end{array}$ \\
\hline Organização & Organização & 3 & Archibald, 2003; Heldman, 2003; Kerzner, 2001 \\
\hline \multirow{5}{*}{$\begin{array}{l}\text { Orientação à } \\
\text { realização }\end{array}$} & Busca por informação & 1 & PMI, 2002 \\
\hline & Iniciativa & 2 & Archibald, 2003; PMI, 2002 \\
\hline & Orientação à realização & 2 & Crawford e Cabanis-Brewin, 2006; PMI, 2002 \\
\hline & Preocupação com ordem & 1 & PMI, 2002 \\
\hline & Solução de problemas & 3 & $\begin{array}{l}\text { Archibald, 2003; Crawford e Cabanis-Brewin, 2006; Heldman, } \\
2003\end{array}$ \\
\hline $\begin{array}{l}\text { Orientação ao serviço } \\
\text { aos clientes }\end{array}$ & $\begin{array}{l}\text { Orientação ao serviço aos } \\
\text { clientes }\end{array}$ & 2 & PMI, 2002; Rabechini Jr, 2005 \\
\hline \multirow[t]{3}{*}{ Planejamento } & Elaboração de orçamento & 1 & Heldman, 2003 \\
\hline & $\begin{array}{l}\text { Habilidade em planejamento e } \\
\text { controle }\end{array}$ & 1 & Archibald, 2003 \\
\hline & Planejamento & 3 & Dinsmore, 1992; Heldman, 2003; Kerzner, 2001 \\
\hline Relacionamento & Construção de relacionamento & 3 & Dinsmore, 1992; PMI, 2002; Rabechini Jr, 2005 \\
\hline \multirow[t]{4}{*}{ Humano } & Desenvolvimento de outros & 1 & PMI, 2002 \\
\hline & Empatia & 1 & PMI, 2002 \\
\hline & Gerenciamento de $\mathrm{RH}$ & 1 & Heldman, 2003 \\
\hline & Relacionamento humano & 2 & Heldman, 2003; Rabechini Jr, 2005 \\
\hline \multirow[t]{3}{*}{ Trabalho em equipe } & Alocação de recursos & 1 & Kerzner, 2001 \\
\hline & Construção de equipes & 3 & Dinsmore, 1992; Heldman, 2003; Kerzner, 2001 \\
\hline & Cooperação e espírito de equipe & 1 & PMI, 2002 \\
\hline \multirow[t]{4}{*}{$\begin{array}{l}\text { Tratamento do projeto } \\
\text { como negócio }\end{array}$} & $\begin{array}{l}\text { Desenvolvimento de novos } \\
\text { negócios }\end{array}$ & 1 & Dinsmore, 1992 \\
\hline & Empreendedorismo & 1 & Kerzner, 2001 \\
\hline & $\begin{array}{l}\text { Tratamento do projeto como } \\
\text { negócio }\end{array}$ & 2 & Cohen e Graham, 2002; Dinsmore, 1992 \\
\hline & $\begin{array}{l}\text { Visão externa (mercados, gru- } \\
\text { pos e pessoas) }\end{array}$ & 2 & Cohen e Graham, 2002; Dinsmore, 1992 \\
\hline \multirow[t]{4}{*}{ Habilidades pessoais } & Autoconfiança & 2 & Crawford e Cabanis-Brewin, 2006; PMI, 2002 \\
\hline & Autocontrole & 2 & Crawford e Cabanis-Brewin, 2006; PMI, 2002 \\
\hline & Flexibilidade & 2 & Archibald, 2003; PMI, 2002 \\
\hline & Motivação & 1 & Verma, 1996 \\
\hline
\end{tabular}


endedora, cedido gentilmente para este estudo. Este teste possui 54 afirmações (estímulos) que caracterizam atitudes ou estilos empreendedores, em relação às quais os respondentes manifestam sua reação (acordo ou desacordo). Cada uma dessas questões está relacionada a uma dimensão (6 delas para a necessidade de autonomia e 12 para cada uma das demais). Para identificar se o gerente de projetos possui ou não aquela dimensão da TEG, ele deve alcançar um mínimo de pontos ( 9 pontos para a necessidade de realização, 4 pontos para a necessidade de autonomia e 8 para cada uma das demais).

Com base nessas informações foi gerada a variável independente deste estudo, o nível de tendência empreendedora do gerente de projetos (NTEger). Se o gerente de projetos tivesse apenas uma ou nenhuma das dimensões de tendência empreendedora, o nível era tido como "muito baixo"; se tivesse duas tendências, o nível era considerado "baixo"; quando tivesse três tendências, era considerado "médio"; com quatro, era tido "alto"; e, para aqueles que tivessem as cinco tendências empreendedoras, o nível era considerado "muito alto".

Complementando o conteúdo do instrumento de pesquisa para avaliação do sucesso do projeto, foi utilizado basicamente o modelo de quatro dimensões de Shenhar et al. (1997), tendo sido incluída a dimensão de impacto na equipe, i.e., o grau de atendimento da satisfação da equipe ao final do projeto. Assim, o nível de sucesso dos projetos (NSprj), entendido como a variável dependente do estudo, foi gerado a partir de dez critérios (atendimento às especificações técnicas; às especificações funcionais; aos objetivos de tempo; aos objetivos de orçamento; às necessidades do cliente; solução de pelo menos um problema operacional importante; utilização do produto final pelo cliente; satisfação do cliente pelo produto entregue; satisfação da equipe em trabalhar no projeto; e impacto positivo do produto final do projeto no desempenho da organização). A partir destes critérios, identificaram-se os dois grupos de projetos: projetos menos bem sucedidos (48 casos) e projetos mais bem sucedidos (116 casos), pela técnica não-hierárquica de conglomerado K-médias (MALHOTRA, 2001).

Para efeito de análise dos dados, à luz da questão central de pesquisa, verificou-se a significância da associação entre o nível de tendência empreendedora do gerente de projetos com o nível de sucesso dos projetos, por intermédio do teste não-paramétrico de WilcoxonMann-Whitney, o mais poderoso no caso de grandes amostras, (SIEGEL, 2006).Foi utilizado o nível de 5\% de significância (ou margem de erro), definindo que os testes estatísticos devem representar $95 \%$ de chance de estarem corretos. O grau da associação da relação entre o nível de tendência empreendedora e o nível de sucesso dos projetos foi feito pelo teste estatístico simétrico Gamma e pelo assimétrico Somers. Na necessidade de se avaliar correlações entre variáveis, quando aplicável, foi utilizado o coeficiente de correlação de Spearman, que é o mais apropriado quando não se pode garantir a normalidade das variáveis (PESTANA; GAGEIRO, 2000), acompanhando a escolha por testes estatísticos não-paramétricos.

\section{Análise e discussão dos resultados}

Inicialmente, como um primeiro foco de análise, foi considerada a distribuição dos projetos mais bem e menos bem sucedidos em cada nível da tendência empreendedora do gerente. A Figura 2 mostra essa distribuição, lembrando que, no total de projetos estudados, segundo os critérios adotados e já comentados na metodologia, os mais bem sucedidos representavam $70 \%$ (116 casos) e os menos bem sucedidos 30\% (48 casos). Observa-se no gráfico que os níveis de tendência empreendedora do gerente de projetos que mais contribuíram para a diferença entre o grupo de projetos menos bem sucedidos e o grupo de projetos mais bem sucedidos foram os referentes a "muito baixa" e "muito alta". No primeiro caso, de um total de 12 gerentes de projetos, com nível de tendência empreendedora muito baixa, 5 projetos foram mais bem sucedidos e 7 projetos foram menos bem sucedidos, refletindo um percentual de 40 e $60 \%$, respectivamente. No segundo caso, para os 24 gerentes de projetos com nível de tendência empreendedora muito alta, 22 projetos foram mais bem sucedidos frente a 2 projetos menos bem sucedidos, gerando um percentual de $90 \%$ e $10 \%$, respectivamente. Portanto, essas evidências indicam uma tendência de se aumentar o NSprj na medida em que se aumenta o NTEger.

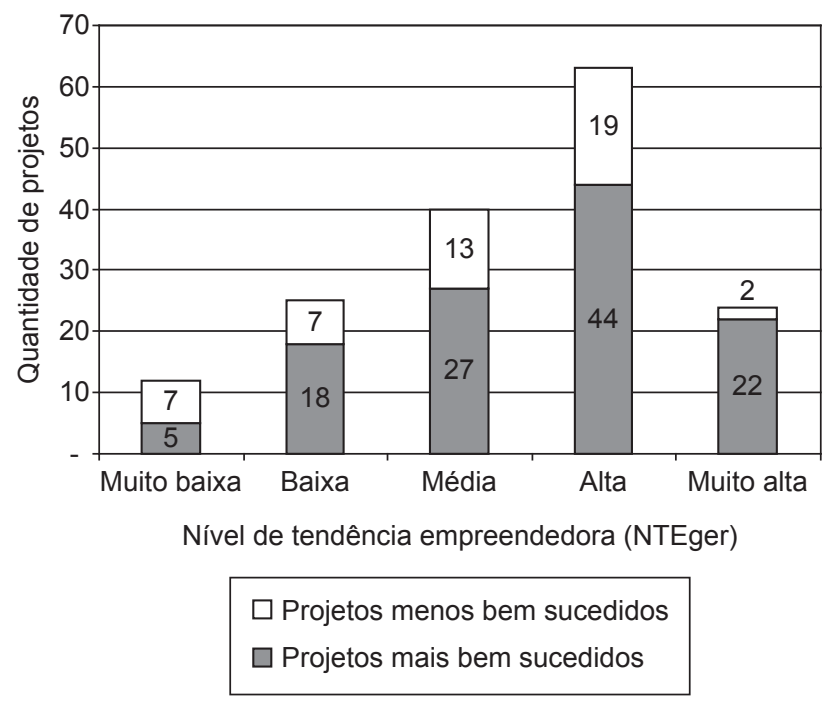

Figura 2. Nível de sucesso dos projetos (NSprj) segundo os níveis de tendência empreendedora dos gerentes (NTEger). 
Os testes estatísticos aplicados para avaliar a relação entre o NTEger e o NSprj estão descritos na Tabela 1. Eles indicam que a associação entre o NTEger e o NSprj é significativa, já que pelo teste de Wilcoxon-Mann-Whitney o valor de significância ficou em $2 \%$, e, portanto, abaixo do limite de 5\% definido para este estudo, confirmando, assim, a tendência verificada acima, de que quanto maior o NTEger, maior a probabilidade dos projetos serem mais bem sucedidos.

Verificando-se que há dependência na relação entre as duas variáveis (NTEger e NSprj) foi analisado o grau de associação entre elas. A estatística Gamma, conforme Tabela 1, mostra também que a relação é significativa $(1,5 \%)$ e que se pode concluir que há uma associação entre as variáveis simetricamente positiva, apesar de o grau de associação se mostrar fraco $(29,5 \%)$. Isto significa que há 29,5\% de probabilidade de se predizer o NSprj a ser obtido em um projeto conhecendo-se o NTEger antecipadamente. Como o Gamma é um teste simétrico, ele também indica que, conhecendo-se o NSprj obtido em um projeto, pode-se indicar, com $29,5 \%$ de probabilidade de acerto, qual foi o NTEger. Complementarmente, o teste estatístico Somers, também descrito na Tabela 1, que avalia a direção da associação, i.e., se o NTEger, variável independente, influencia de alguma forma o NSprj, variável dependente, indica que a associação existe e é significativa $(1,5 \%)$ e existindo $12,3 \%$ de previsibilidade do nível de sucesso dos projetos sabendo-se previamente o nível de tendência empreendedora do gerente, o que denota um grau de associação fraco entre ambas.

Todas essas interpretações devem ser consideradas, evidentemente, à luz das limitações convencionais de um estudo típico na área comportamental. De fato, para que um projeto seja bem sucedido, há vários outros fatores (PINTO; KHARBANDA, 1995) que o influenciam, como: uma missão bem definida, apoio da gerência superior, um planejamento detalhado, consulta às expectativas e necessidades do cliente, membros da equipe qualificados para o trabalho a ser desenvolvido, disponibilidade tecnológica para o desenvolvimento do produto, aceitação do projeto pelo cliente, monitoramento e feedback da execução do projeto, comunicação adequada entre os envolvidos no projeto e habilidade de solucionar os problemas durante $\mathrm{o}$ projeto. Vários desses fatores não dependem diretamente do esforço e características do gerente de projetos, e, por isso, a associação das características empreendedoras do gerente com o nível de sucesso do empreendimento, mesmo que fraca, parece mostrar a sua relevância no processo de gerenciamento dos projetos.

Um segundo foco de análise é a correlação de cada dimensão da tendência empreendedora do gerente com cada um dos critérios de sucesso do projeto utilizados neste estudo, conforme demonstra a Tabela 2. O índice de correlação positivo entre a dimensão de necessidade de realização e o atendimento dos objetivos de orçamento, conforme demonstra a referida tabela, pode indicar que provavelmente este deve ser um critério forte nas expectativas dos envolvidos no projeto das organizações pesquisadas, sinalizando que os respectivos gerentes devessem orientar mais sua atenção para garantir seu cumprimento. Esta dimensão esteve presente em $77 \%$ dos casos. Por outro lado, a dimensão de tendência empreendedora referente à necessidade de autonomia, como uma das menos presentes nos gerentes de projetos (30\%), mostrou-se significativa e negativamente correlacionada com o impacto do projeto na organização. Isto pode ser entendido como um indício de que o gerente de projetos normalmente tem dificuldades de entender o significado de um bom projeto do ponto de vista global, não necessariamente atrelado ao seu ambiente mais próximo. Isto também pode ser explicado pelo fato de que muitos gerentes evoluem de uma posição técnica, normalmente marcada por graus elevados de autonomia e de apego ao próprio trabalho (MEDCOF, 1985).

De uma forma destacada, a dimensão de tendência criativa, apesar de ter sido uma das que menos os gerentes de projetos apresentaram neste estudo (62\%), correlacionou-se com 10 dos 17 critérios de sucesso, além do NSproj global, e sempre de uma forma positiva. É interessante notar que esta dimensão foi a única a não ser citada como uma característica do gerente de projetos segundo os estudos pesquisados neste trabalho. É importante salientar que dimensão de tendência criativa está correlacionada com fatores de sucesso em todas as dimensões, apesar do grau de correlação não ser muito alto: eficiência do projeto, satisfação do cliente, da equipe e da organização executora, assim como tende a gerar novos mercados. Isto evidentemente suscita a necessidade de novos estudos nessa direção.

A dimensão de propensão ao risco mostrou-se positivamente correlacionada com a satisfação do cliente em relação ao produto final entregue, estando presente em $75 \%$ dos casos. Provavelmente a capacidade do gerente de projetos de agir com informações incompletas e enfrentar desafios geraram produtos que atenderam ou

Tabela 1. Grau de associação entre NTEger e NSprj segundo diferentes testes.

\begin{tabular}{ccccccc}
\hline \multicolumn{2}{c}{ Wilcoxon-Mann-Whitney } & \multicolumn{2}{c}{ Gamma } & \multicolumn{2}{c}{ Somers'd } \\
\cline { 1 - 5 } \cline { 5 - 8 } & Sig. Assimp. & Valor & Sig. Aprox. & Valor & $12,3 \%$ & $1,5 \%$ \\
\hline$-2,319$ & $2 \%$ & $29,5 \%$ & $1,5 \%$ & Sig. Aprox. \\
\hline
\end{tabular}


mesmo superaram as expectativas dos clientes, já que estes, dependendo da área de negócio, muitas vezes não conseguem transmitir de forma precisa as características do produto final que desejam. Normalmente, cabe ao gerente de projetos captar e entender essas necessidades.

Como destaque negativo, vale mencionar a dimensão de Impulso e Determinação. Apesar de ter sido a tendência empreendedora que os gerentes de projetos mais demonstraram possuir (92\%), incluindo a característica de liderança, não foi possível correlacioná-la com nenhum critério de sucesso utilizado. Indagações, portanto, permanecem aqui para futuros estudos.
Finalmente, como um terceiro e último foco de análise, verifica-se agora a existência ou não da associação entre cada dimensão de tendência empreendedora do gerente com o NSprj, este último visto de forma global, conforme já se definiu. Como pode ser verificado na Tabela 3, apenas a dimensão de tendência criativa dos gerentes de projetos apresenta uma associação significativa $(4,5 \%)$ com o NSprj, confirmando a correlação identificada no foco de análise anterior, ainda que de forma diferenciada segundo os diferentes critérios de sucesso. Isto parece indicar que o projeto tende a ser mais bem sucedido quando o gerente de projetos possui mais esta tendência,

Tabela 2. Correlação entre as dimensões de tendência empreendedora do gerente e os critérios de sucesso dos projetos.

\begin{tabular}{|c|c|c|c|c|c|c|c|}
\hline \multirow{2}{*}{$\begin{array}{l}\text { Dimensão de } \\
\text { sucesso }\end{array}$} & \multirow[t]{2}{*}{ Critérios de sucesso } & \multirow[t]{2}{*}{$\mathbf{N}$} & \multicolumn{5}{|c|}{ Dimensão de tendência empreendedora } \\
\hline & & & $\begin{array}{l}\text { Necessidade } \\
\text { de realização }\end{array}$ & $\begin{array}{c}\text { Necessidade } \\
\text { de autonomia }\end{array}$ & $\begin{array}{c}\text { Tendência } \\
\text { criativa }\end{array}$ & $\begin{array}{c}\text { Propensão ao } \\
\text { risco }\end{array}$ & $\begin{array}{c}\text { Impulso e } \\
\text { determinação }\end{array}$ \\
\hline \multirow{2}{*}{$\begin{array}{l}\text { Eficiência } \\
\text { do Projeto }\end{array}$} & Prazo & 164 & 0.153 & -0.035 & $0.172(*)$ & 0.087 & 0.129 \\
\hline & Custo & 164 & $0.180(*)$ & 0.04 & $0.166(*)$ & 0.14 & 0.112 \\
\hline \multirow[t]{6}{*}{ Impacto no cliente } & Especificações técnicas & 164 & 0.013 & -0.116 & 0.126 & 0.001 & 0.089 \\
\hline & Especificações funcionais & 164 & 0.078 & -0.113 & $0.163(*)$ & 0.075 & 0.103 \\
\hline & Necessidades do cliente & 164 & 0.092 & -0.12 & $0.289(* *)$ & 0.131 & 0.087 \\
\hline & $\begin{array}{l}\text { Atendimento ao problema } \\
\text { mais importante }\end{array}$ & 164 & 0.004 & -0.152 & 0.125 & 0.057 & -0.025 \\
\hline & Uso atual & 164 & 0.014 & -0.146 & $0.205(* *)$ & 0.1 & -0.022 \\
\hline & Produto final & 164 & 0.059 & -0.125 & $0.207(* *)$ & $0.171(*)$ & 0.024 \\
\hline \multirow[t]{4}{*}{$\begin{array}{l}\text { Sucesso direto } \\
\text { no negócio }\end{array}$} & $\begin{array}{l}\text { Desempenho da } \\
\text { organização }\end{array}$ & 164 & -0.034 & $-.196(*)$ & $0.158(*)$ & 0.137 & -0.027 \\
\hline & Sucesso comercial & 112 & 0.022 & -.0 .144 & $0.191(*)$ & 0.129 & 0.01 \\
\hline & $\begin{array}{l}\text { Aumento na fatia de } \\
\text { mercado }\end{array}$ & 112 & 0.001 & -0.084 & 0.089 & 0.108 & -0.111 \\
\hline & Diminuição de custos & 120 & -0.004 & -0.071 & 0.033 & -0.034 & -0.152 \\
\hline \multirow[t]{4}{*}{$\begin{array}{l}\text { Preparação para } \\
\text { o futuro }\end{array}$} & $\begin{array}{l}\text { Novo mercado para a } \\
\text { organização }\end{array}$ & 93 & 0.112 & 0.007 & $0.217(*)$ & 0.131 & 0.025 \\
\hline & Nova linha de produtos & 101 & 0.059 & -0.038 & 0.187 & 0.125 & 0.009 \\
\hline & Nova tecnologia & 115 & 0.016 & -0.073 & 0.112 & 0.118 & 0.062 \\
\hline & Nova competência & 131 & 0.124 & -0.042 & 0.042 & 0.054 & -0.062 \\
\hline Impacto na equipe & Satisfação da equipe & 164 & 0.09 & -0.101 & $0.192(*)$ & 0.085 & 0.045 \\
\hline \multicolumn{2}{|c|}{ Nível de Sucesso dos projetos (NSprj) } & 164 & 0.099 & -0.076 & $0.157(*)$ & 0.106 & 0.1 \\
\hline
\end{tabular}

* Correlação é significativa no nível de 5\% (conforme coeficiente de correlação de Spearman) ** Correlação é significativa no nível de $1 \%$ (idem).

Tabela 3. Associação entre as dimensões de tendência empreendedora do gerente de projetos com NSprj, segundo diferentes testes estatísticos.

\begin{tabular}{|c|c|c|c|c|c|c|}
\hline \multirow{2}{*}{$\begin{array}{c}\text { Dimensão de tendência } \\
\text { empreendedora }\end{array}$} & \multicolumn{2}{|c|}{ Wilcoxon-Mann-Whitney } & \multicolumn{2}{|c|}{ Gamma } & \multicolumn{2}{|c|}{ Somers'd } \\
\hline & $\mathbf{Z}$ & Sig. Assimp. (\%) & Valor & Sig. Aprox & Valor & Sig. Aprox. \\
\hline Necessidade de realização & $-1,260$ & 20,8 & & & & \\
\hline Necessidade de autonomia & $-0,977$ & 32,9 & & & & \\
\hline Tendência criativa & $-2,003$ & 4,5 & $22,5 \%$ & $4,8 \%$ & $9,4 \%$ & $4,8 \%$ \\
\hline Propensão ao risco & $-1,356$ & 17,5 & & & & \\
\hline Impulso e determinação & $-1,279$ & 20,1 & & & & \\
\hline
\end{tabular}


como parte de suas características pessoais. Os testes Gamma e Somers também confirmam a significância da relação. Segundo o primeiro teste, evidencia-se aqui uma tendência de se identificar se o projeto será mais bem sucedido, com probabilidade de $22,5 \%$ de acerto, se se souber antecipadamente o valor da tendência criativa do gerente de projetos, e vice-versa.

Por fim, ainda com base nos dados da Tabela 3, verifica-se que o teste Somers indica que há uma associação positiva, apesar de seu grau ser muito fraco, entre a tendência criativa do gerente de projetos com o NSprj. Isto significa que se pode conhecer, com 9,4\% de probabilidade de acerto, o nível de sucesso do projeto, conhecendo-se antecipadamente o nível da tendência criativa do gerente de projetos. Novamente, as limitações dessas conclusões devem ser reafirmadas, tratando-se particularmente de estudos nas áreas sociais.

\section{Conclusões e considerações finais}

Reconhecendo-se que o grau de empreendedorismo do gerente é apenas um dos fatores de sucesso de projetos, este trabalho procurou evidenciar, a partir de um estudo de campo envolvendo 164 projetos, se as características empreendedoras de seus respectivos gerentes se refletiam em projetos mais bem sucedidos do ponto de vista organizacional.

Pode-se dizer, dentro da amostra pesquisada, que há indicações de que quanto maior a tendência empreendedora do gerente de projetos, maior será a possibilidade de que os projetos por ele comandados sejam mais bem sucedidos. Esta relação possui um grau de associação baixo, porém somente a constatação de sua existência, em algum grau, já revela a importância desta característica. Pode-se assim concluir uma vez que:

a) as características de um gerente de projetos competente abrangem muitas outras, além da tendência empreendedora, que foi o foco deste estudo, tais como: conhecimento da área de aplicação do produto do projeto, habilidades interpessoais, entendimento do contexto do gerenciamento do projeto, conhecimento de técnicas e práticas de administração geral e de projetos, etc;

b) existem inúmeros fatores críticos de sucesso com baixo grau de dependência da atuação específica do gerente de projetos, como: maturidade da organização em relação ao gerenciamento de projetos, definição clara da missão do projeto, demasiada dependência de tecnologia, expectativas do contratante e do contratado, comprometimento do patrocinador, fornecimento dos recursos necessários ao bom andamento do projeto, etc.
Mais especificamente, na avaliação de cada dimensão de tendência empreendedora do gerente com os critérios de sucesso dos projetos, percebe-se adicionalmente:

a) necessidade de realização: dimensão que compreende orientação a resultados e tarefas, auto-suficiência, persistência e determinação, apresenta-se correlacionada positivamente com o critério de atendimento ao custo, tendendo a indicar que os gerentes de projetos que possuem esta dimensão têm uma preocupação maior com a eficiência do projeto, ainda que com uma visão mais orientada a curto prazo comparativamente a outras dimensões de sucesso;

b) necessidade de autonomia: dimensão que compreende preferência por trabalhar sozinho, fazer coisas pouco convencionais e decidir sem receber ordens, de um lado, foi encontrada em uma minoria dos gerentes de projetos estudados. De outro lado, observa-se uma correlação negativa dessas caraterísticas com a contribuição do projeto para o desempenho da organização-mãe, tendendo a demonstrar a falta de visão dos gerentes sobre as necessidades organizacionais mais amplas, em contraposição ao fato de tenderem a se concentrar em suas próprias necessidades;

c) tendência criativa: dimensão que se caracteriza pela inovação, criação de muitas idéias, versatilidade, intuição, gosto por desafios, novidade e mudança. Neste estudo, apresenta-se correlacionada com vários critérios de sucesso, em todas as suas dimensões, como eficiência do projeto, impacto no cliente, impacto direto no negócio e preparação para o futuro, mostrando que as suas características tendem a afetar de maneira global o desempenho do projeto. Conseqüentemente, parece que os projetos podem ser mais bem sucedidos quanto maior for a tendência criativa do gerente. Essa conclusão deve ser vista como preliminar e deve ser mais bem estudada no futuro;

d) propensão ao risco: mostrou-se correlacionada positivamente com a satisfação do cliente em relação ao produto final entregue, indicando que a capacidade do gerente de projetos de agir com informações incompletas e enfrentar desafios, características típicas desta dimensão, conseguiram auxiliá-lo a gerar produtos com a especificidade esperada pelos clientes; e

e) impulso e Determinação: para esta dimensão não se identificou qualquer correlação com os critérios de sucesso, provavelmente pelo fato de que a grande maioria dos gerentes de projetos a possui, já que suas características parecem ser relevantes para eles, tais como: aproveitamento das oportunidades, autoconfiança e determinação para realizar o projeto com equilíbrio entre o resultado e o esforço. 
A titulo de destaque das conclusões, cabe comentar que a identificação da tendência criativa como a única dimensão associada ao nível de sucesso do projeto traz como consequiência a indicação de que pessoas tenderiam a ter estas características para desempenhar seu papel de uma maneira mais efetiva. Como não foi encontrada a menção destas características nos autores pesquisados neste estudo, recomenda-se a revisão do perfil do gerente de projetos, na tentativa de se avaliar mais profundamente a inclusão da tendência criativa no escopo de suas habilidades críticas e, conseqüentemente, de seu provável impacto.

No século XXI, um gerente de projetos não pode ser visto mais como um mero executor, mas como um parceiro importante no reconhecimento e busca de novas oportunidades, além da contribuição aos bons resultados pela persistência na solução dos problemas e enfrentamento dos desafios encontrados no desenrolar das suas atividades. As associações positivas, ainda que de baixa magnitude, encontradas entre o nível de tendência empreendedora do gerente com o nível de sucesso dos projetos reforçam a indicação de que as organizações precisam se preocupar em criar mecanismos incentivadores para essa função, como, por exemplo, visão e estratégias claras; estímulo à diversidade; cultura interna propícia; instrumentos motivacionais (além de recompensas financeiras e prêmios, reconhecimento, visibilidade e auto-realização). Ao mesmo tempo, seria importante limitar e restringir os fatores inibidores ao aparecimento e aproveitamento das características empreendedoras do gerente de projetos, como burocracia, centralização de poder, cultura resistente a mudanças, ambiente tradicional e paternalista.
Ambas as situações poderiam ajudar as empresas a terem projetos mais bem sucedidos.

Como limitações e restrições do alcance das conclusões aqui mencionadas, a mais importante talvez se refira aos respondentes utilizados para este estudo. Como já se mencionou, definiu-se o gerente de projetos como único respondente do questionário pelo tipo de avaliação empregada para se identificar as características de um empreendedor corporativo, no caso o Teste TEG, que exige que a resposta seja dada pelo próprio gerente de projetos. A utilização de outro tipo de respondente para preencher outras partes do questionário, por exemplo, sobre as questões referentes ao sucesso, dificultaria o alcance de um alto número de respondentes, trazendo outro tipo de limitações para o estudo. Outro problema derivado da escolha do gerente de projetos como respondente único é, sem duvida, o seu viés otimista na avaliação do produto do seu trabalho, como verificado pela alta participação de projetos tidos como mais bem sucedidos (70\% da amostra). Esses problemas poderiam ser tratados e melhor resolvidos em estudos futuros, nos quais se poderia entrevistar, além do gerente de projetos, o patrocinador e o cliente ou usuário, assim como a equipe, para se obter uma visão mais completa e abrangente acerca de determinados fenômenos, como êxito, por exemplo. Independentemente de seu mérito, portanto, as conclusões deste estudo devem ser entendidas do ponto de vista dos gerentes de projetos que responderam ao estudo e devem ser válidas apenas para a amostra de projetos estudada, dadas as dificuldades de se avaliar sua representatividade no contexto geral dos projetos existentes no ambiente brasileiro.

\title{
Manager entrepreneur tendency: an analysis of its relevance to innovative projects success
}

\begin{abstract}
A project manager as a leader is the key element to assure the success of the ventures he/she is responsible for and to implement the organization strategies. Besides, the project manager can be very important to the future of the organization by applying entrepreneur skills aiming at needs and new opportunities. However, he/she has operational responsibilities such as planning, monitoring, and accounting and control of the project which can, some times, conflict with characteristics of an entrepreneur. Therefore, it is relevant to evaluate whether a project manager has the required entrepreneur skills which when combined the skills of a manger result in successful projects. In order to perform this evaluation, a study with 164 graduate and highly experienced project managers, most men, was carried out. A Nonparametric analysis indicated that the greater the project manager's entrepreneur tendency, the more successful the projects can be conceived. The creative tendency proved important since the results demonstrated a number of success criteria associated.
\end{abstract}

Keywords: Project manager. Corporate entrepreneurship. Project success. Enterprising tendency. 
ANDREASSI, T. Empreendedorismo Corporativo. GV Executivo, v. 4, n. 3, ago./out. 2005.

ARCHIBALD, R. D. Managing high-technology programs and projects. 3. ed. New Jersey: John Wiley \& Sons, 2003.

BIRLEY, S.; MUZYKA, D. F. (eds.). Dominando os desafios do empreendedor. São Paulo: Pearson Education Brasil, 2001.

CAIRD, S. Testing enterprising tendency of occupational groups. British Journal of Management. v. 2, p. 177-183, 1991.

CLELAND, D. I. Project leadership in project management: strategic design and implementation. 3. ed. New York: McGrawHill, 1999.

COHEN, D. J.; GRAHAN, R. J. Gestão de projetos: MBA Executivo. Rio de Janeiro: Campus, 2002.

CRAWFORD, J. K.; CABANIS-BREWIN, J. Optimizing human capital with a strategic project office: select, train,measure, and reward people for organization success. Boca Raton: Auerbach, 2006.

CRAWFORD, L.; HOBBS, B.; TURNER, J. R. Aligning capability with strategy: categorizing projects to do the right projects and to do them right. Project Management Journal, v. 37, n. 2, p. 38-50, jun. 2006.

DINSMORE, P. C. Gerência de programas e projetos. São Paulo: Pini, 1992

DINSMORE, P. C. (ed.). The AMA handbook of project management. New York: Amacon, 1993.

HASHIMOTO, M. Espírito empreendedor nas organizações: aumentando a competitividade através do intraempreendedorismo. São Paulo: Saraiva, 2006.

HELDMAN, K. Gestão de projetos: guia para o exame oficial do PMI. Tradutor: Félix, Teresa. Rio de Janeiro: Bookman, 2003.

HISRICH, R. D.; PETERS, M. P. Establishing a new business venture unit within a firm. Journal of Business Venturing, v.1, n.3, 307-322, 1986.

JONES, G. R.; BUTLER, J. E. Managing Internal Corporate Entrepreneurship: An Agency Theory Perspective. Journal of Management, v. 18, n. 4, p. 733-749, dec. 1992.

JUGDEV, K.; MÜLLER, R. A retrospective look at our evolving understanding of project success. Project Management Journal, v. 36, n. 4, p. 19-31, dec. 2005.

KERZNER, H. Project management - a systems approach to planning, scheduling, and controlling. 7. ed. Ohio: John Wiley \& Sons, 2001

KERZNER, H. Gestão de projetos: as melhores práticas. Tradutora: Teresa Felix. Rio de Janeiro: Campus, 2003.

LUCHSINGER, V.; BAGBY, D. R. Entrepreneurship and Intrapreneurship: Behaviors, Comparisons, and Contrasts. S.A.M. Advanced Management Journal, v. 52, n. 3, p. 10-13, summer 1987.

LUMPKIN, G. T.; DESS, G. G. Clarifying the entrepreneurial orientation construct and linking it to performance. The Academy of Management Review, v. 21, n. 1, p. 135-172, jan 1996.

MALHOTRA, N. Pesquisa de Marketing: uma orientação aplicada. Trad. Nivaldo Montigelli Jr e Alfredo Alves de Farias. 3. ed. Porto Alegre: Bookman, 2001.

MEDCOF, J. W. Training technologists to become managers. Research Management, v. 18, n. 1, p. 18-21, jan-feb, 1985.
MEREDITH, J. R.; MANTEL JR., S. J. Administração de Projetos: uma abordagem gerencial. Tradutor: CIERCO, A. A.; ZOTES, L. P.. Rio de Janeiro: LTC, 2003.

MORRIS, P.; JAMIESON, A. Translating corporate strategy into project strategy: realizing corporate strategy through project management. Local: PMI, 2004. Disponível em: <http://pmi. books $24 \times 7$.com/viewer.asp? bookid=9343\&chunkid $=0639557$ 031>. Acesso em: 5 nov. 2006.

PESTANA, M. H.; GAGEIRO, J. N. Análise de dados para ciências sociais - a complementaridade do SPSS. Lisboa: Sílabo, 2000.

PINCHOT III, G. Intrapreneuring: por que você não precisa deixar a empresa para tornar-se um empreendedor. Traduzido por Nivaldo Montingelli Júnior. São Paulo: Harbra, 1989.

PINTO, J. K.; KHARBANDA, O. P. Sucessful projects managers: leading our team to success. New York: Van Nostrand Reinhold, 1995

PINTO, J. K.; SLEVIN, D. P. Project Success: Definitions and Measurement Techniques. Project Management Journal, v. 19, n. 1, p. 67-72. 1988.

PROJECT MANAGEMENT INSTITUTE - PMI. Project manager competency development (PMCD) framework. Newton Square: Project Management Institute, 2002.

PROJECT MANAGEMENT INSTITUTE - PMI. PMBOK - Um Guia do Conjunto de Conhecimentos em Gerenciamento de Projetos. 3. ed. Newton Square : Project Management Institute, 2004.

RABECHINI JR., R. O gerente de projetos na empresa. São Paulo: Atlas, 2005.

SBRAGIA, R.; MAXIMIANO, A.; KRUGLIANSKAS, I.. O gerente de projetos: seu papel e habilidades. Revista de Administração, v. 21, n. 3, p. 24-31, jul.-set. 1986.

SCHUMPETER, J. A. Economic theory and entrepreneurial history In: Change and the entrepreneur: postulates and patterns of Entrepreneurial history. Cambridge-Mass: Harvard University Press, 1949.

SELLTIZ,C.; WRIGHTSMAN, L.S., COOK, S.W., KIDDER, L.H.. Métodos de pesquisa nas relações sociais - Delineamentos de pesquisa. Trad: Maria M. H. d’Oliveira, Miriam M. Del Rey. 2. ed. São Paulo: EPU, 1987.

SHENHAR, A. J.; LEVY, O.; DVIR, D. Mapping the Dimensions of Project Success. Project Management Journal, v. 28, n. 2, p. 5-13, jun. 1997.

SIEGEL, S. CASTELLAN JR, N. J. Estatística não-paramétrica para as ciências do comportamento. Tradução: Sara I. C. Carmona. 2. ed. Porto Alegre: Artmed, 2006.

SIQUEIRA, E. Convergência digital: o desafio da mudança de paradigmas. In: SEMINÁRIO INTERNACIONAL DE IMPRENSA E MULTIMÍDIA, 1., Brasília, 2006. Disponível em <http://www.portalimprensa.com.br/imprensamultimidia/ apresentacoes.asp>. Acesso em: 15 jul. 2006.

VERMA, V. K. The Human Aspects of Project Management: Human Resources Skills for the Project Manager. Volume Two. Newton Square: Project Management Institute: 1996. Disponível em: <http://pmi.books24x7.com/viewer.asp>. Acessado em: 20 jun. 2006. 


\section{Sobre os autores}

\section{Rosária de Fátima Segger Macri Russo}

\section{Roberto Sbragia}

Faculdade de Economia, Administração e Contabilidade, Universidade de São Paulo, USP, Av. Professor Luciano Gualberto, 908, CEP 05508-900, sala E117, São Paulo, SP, Brasil, e-mails: rosaria@pmisp.org.br; rsbragia@usp.br 
